\title{
Cost effectiveness of strategies to combat vision and hearing loss in sub-Saharan Africa and South East Asia: mathematical modelling study
}

\author{
OPEN ACCESS
}

\author{
Rob Baltussen senior researcher ${ }^{1}$, Andrew Smith honorary professor ${ }^{2}$ \\ 'Department of Primary and Community Care, Radboud University Nijmegen Medical Center, PO Box $91016500 \mathrm{HB}$ Nijmegen, The Netherlands; \\ ${ }^{2}$ Centre for Disability and Development, London School of Hygiene and Tropical Medicine, London, UK
}

\begin{abstract}
Objective To determine the relative costs, effects, and cost effectiveness of selected interventions to control cataract, trachoma, refractive error, hearing loss, meningitis and chronic otitis media.

Design Cost effectiveness analysis of or combined strategies for controlling vision and hearing loss by means of a lifetime population model.

Setting Two World Health Organization sub-regions of the world where vision and hearing loss are major burdens: sub-Saharan Africa and South East Asia.

Data sources Biological and behavioural parameters from clinical and observational studies and population based surveys. Intervention effects and resource inputs based on published reports, expert opinion, and the WHO-CHOICE database.

Main outcome measures Cost per disability adjusted life year (DALY) averted, expressed in international dollars (\$Int) for the year 2005.

Results Treatment of chronic otitis media, extracapsular cataract surgery, trichiasis surgery, treatment for meningitis, and annual screening of schoolchildren for refractive error are among the most cost effective interventions to control hearing and vision impairment, with the cost per DALY averted $<\$$ Int285 in both regions. Screening of both schoolchildren (annually) and adults (every five years) for hearing loss costs around $\$$ Int1000 per DALY averted. These interventions can be considered highly cost effective. Mass treatment with azithromycin to control trachoma can be considered cost effective in the African but not the South East Asian sub-region.
\end{abstract}

Conclusions Vision and hearing impairment control interventions are generally cost effective. To decide whether substantial investments in these interventions is warranted, this finding should be considered in relation to the economic attractiveness of other, existing or new, interventions in health.

\section{Introduction}

Throughout the world, loss of vision and hearing are a major burden. More than 284 million people are visually impaired, of whom 245 million have low vision and 39 million are blind. ${ }^{1}$ Some 278 million people worldwide have moderate or greater hearing impairment..$^{2-5}$ The number of people worldwide with sensory deficits is rising mainly due to a growing global population and longer life expectancies. More than $90 \%$ of the world's visually impaired people and $80 \%$ of hearing impaired people live in low and middle income countries. ${ }^{16}$

Cataract is the leading cause of visual impairment globally, followed by glaucoma. The most common type of hearing impairment is sensorineural hearing loss (with common causes advanced age and noise exposure), followed by conductive hearing impairment (with leading cause chronic otitis media). Globally, up to $75 \%$ of all vision loss and $50 \%$ of hearing loss is avoidable. ${ }^{16}$

For this reason, global initiatives have set targets and indicators related to the reduction of vision and hearing impairment, with special reference to low and middle income countries. VISION 2020, the global initiative for the elimination of avoidable blindness, aims to eliminate avoidable blindness by the year 2020 and prevent the projected doubling of avoidable visual impairment between 1990 and 2020. ${ }^{7}$ WWHearing (World-Wide Hearing Care for Developing Countries) aims to eliminate much of avoidable hearing loss by 2020 through a new initiative called Audio 2020. ${ }^{8}$ 
For many countries, it is not evident that these targets will be achieved at current rates of progress, despite a wide range of effective interventions to prevent, detect, and manage visual and hearing impairment. A key question, therefore, is whether the correct mix of interventions is currently being used, and what strategies should be scaled up if additional funds would become available. Cost and cost effectiveness analyses can provide valuable inputs to these decisions by identifying the most efficient ways of delivering prevention, diagnosis, and treatment services at different levels of resource availability.

Several studies have reported on the global and regional cost effectiveness of interventions targeting cataract, ${ }^{9}$ trachoma, ${ }^{10}$ refractive error, ${ }^{11}$ and different causes of hearing impairment. ${ }^{12}$ However, studies have been carried out in isolation, which prevents the cost effectiveness of the different interventions being directly compared. In addition, the studies used demographics and price levels for the year 2000.

Now, a decade past 2000, and in the realm of the global initiatives, an up to date assessment of the cost effectiveness of vision and hearing impairment control strategies is needed. In this paper we address the question of what are the costs and effects of prevention, early detection, management, and rehabilitation of visual and hearing impairment, both singly and in combination. Our analysis is based on a consistent methodological approach and a generic measure of effectiveness and covers two geographical settings, in Asia and Africa.

\section{Methods}

\section{General approach}

Cost effectiveness analysis can be undertaken in many ways, and there have been several attempts to develop methodological guidelines to make results more comparable. In its WHO-CHOICE project, the World Health Organization has developed a standardised set of methods and tools that can be used to analyse the societal costs and effectiveness of current and possible new interventions simultaneously. ${ }^{13}{ }^{14}$ The project is designed to provide regularly updated databases on the costs and the effects of a full range of promotive, preventive, curative, and rehabilitative health interventions.

\section{Regions analysed}

Most countries do not have the capacity to evaluate all potential interventions for improving given health indicators at the national and the sub-national level, and global estimates are too general and of little use to any specific country. However, countries may benefit from regional evaluations of data, where data of neighbouring countries with similar settings are pooled. The present analysis drew on a comprehensive examination of 14 world sub-regions defined by geographical proximity and epidemiology according to WHO classification. In common with other papers in this series, we evaluated interventions for two major global regions using a standardised analytical approach. The two regions are referred to as sub-Saharan Africa, including those African countries with very high adult and high child mortality (referred to as AfrE in the WHO classification), and South East Asia, including those countries in Asia with high adult and high child mortality (referred to as SearD). ${ }^{15}$ The prevalence of vision and hearing impairment globally and for these two regions is summarised in table $1 \Downarrow$ (based on Resnikoff et $\mathrm{al}^{16}{ }^{17}$ and Mathers ${ }^{18}$ ).

\section{Interventions analysed}

Table $2 \Downarrow$ shows the set of 87 analysed interventions (and combinations of interventions) to control cataract, trachoma, refractive error, hearing loss, meningitis, or chronic otitis media. We carefully selected the interventions on their relevance for disease control but were also limited by the lack of data on burden of disease or intervention effectiveness. Some interventions that have relatively recently been developed were not subjected to analyses. The resulting set of interventions is therefore somewhat arbitrary and not meant to cover all potentially available interventions to reduce hearing and vision loss in sub-Saharan Africa and South East Asia. For example, in trachoma control we evaluated antibiotic treatment and surgery but not promotion of face washing. Likewise, in cataract control, we evaluated extracapsular cataract extraction but not small incision cataract surgery or phacoemulsification. In control of hearing impairment, we did not evaluate education, rehabilitation, and noise conservation programmes, nor neonatal screening, surgical interventions, or cochlear implants. Interventions on glaucoma were also not evaluated. All interventions are defined in appendix A on bmj.com.

All interventions were analysed at WHO-CHOICE standardised geographic coverage levels of $50 \%, 80 \%$, and $95 \%$, referring to the percentage of eligible cases receiving treatment. These levels may not always be feasible, but are nevertheless reported here to show the presence of important (dis)economies of scale when varying the number of people covered.

\section{Estimating health effects}

The starting point of our analysis of health effects was the identification of best available evidence on the (clinical or population) effectiveness of interventions. Ideally, we retrieved this evidence from Cochrane reviews (such as on the effectiveness of cataract surgery), but in other instances we used evidence from individual studies (such as on the effectiveness of azithromycin in trachoma control). Where no evidence was available, we based our estimate of effectiveness on expert opinion (such as on levels of compliance in wearing hearing aids or glasses). We used evidence on intervention effectiveness pertaining to the regions under study or extrapolated this from Western settings where meaningful (as for antibiotic treatment for meningitis). All sources of data of intervention effectiveness for screening interventions for uncorrected refractive error are listed in table $3 \Downarrow$, and those for the other disease areas are listed in the appendices on bmj.com.

All analyses used population model PopMod ${ }^{19}$ to translate this intervention effectiveness into a generic measure of health effects. More specifically, it combines incidence, prevalence, and mortality data for the relevant causes of vision and hearing impairment with the standard health state valuations ${ }^{20}$ to estimate the population impact of the different scenarios in terms of healthy years lived. ${ }^{14}$ Following standardised WHO-CHOICE cost effectiveness analysis, we evaluated all interventions for a period of 10 years, and ran model for the length of time necessary for all people affected by the interventions to have died (that is, some 100 years in both regions, following the use of regional mortality rates ${ }^{18}$ ). The difference between the healthy years lived in each intervention scenario and the no intervention scenario is the health gain of the intervention, or the number of disability adjusted life years (DALYs) averted. A general description of the population model is provided in the general appendix on bmj.com, and details of the different disease models are available in appendix A on bmj.com. 


\section{Estimating costs}

The analysis follows standardised WHO-CHOICE guidelines on costing analysis, and estimates patient level costs and programme level costs from the societal perspective. Patient level costs are all costs incurred at the level of contact between the provider and the individual patient. The quantities of resources required in terms of diagnostic tests, drug use, and health centre visits for supervision and monitoring and hospitalisation for each of the interventions were based on WHO treatment protocols and expert opinion of actual practice. Drug costs were based on international drug prices ${ }^{21}$ with a mark up for international and local transportation costs. ${ }^{22}{ }^{23}$ Unit costs of health centre visits and hospital inpatient days were based on econometric analysis by Adam et al, ${ }^{24}$ while those for laboratory tests and $\mathrm{x}$ rays were based on the best available international cost information included in WHO-CHOICE's costing database. Unit costs were combined with resource use patterns to estimate the cost per patient treated. Total patient costs were then calculated as the cost per patient treated multiplied by the number of patients treated (calculated as the annual incidence of disease from the model multiplied by the relevant coverage level and then by the percentage of cases diagnosed and treated in covered areas). The costs of screening interventions to detect hearing and vision impairment not only include the costs of the screening activities but also costs of hearing aids and glasses for those who need them.

Programme level costs relate to the resource inputs used in the production of an intervention at a level above that of the patient or providing facility, such as central planning and administration functions, supervision, and training. Estimated quantities of resources required for central planning and administration at national, provincial and district levels were based on a series of evaluations made by WHO-CHOICE costing experts in the different sub-regions and validated against the literature (categories of resource input included personnel, training, materials and supplies, media, transport, maintenance, utilities and capital. ${ }^{22}$ Details of all cost calculations are found in appendix A on bmj.comand previously published papers. ${ }^{9-12} \mathrm{An}$ example of all variable inputs including its sources is provided in table $3 \Downarrow$, for the cost effectiveness analysis of screening strategies for uncorrected refractive error among schoolchildren in sub-Saharan Africa.

Following the WHO-CHOICE standardised approach, we assumed that interventions were performed optimally (that is, no undertreatment or overtreatment at the highest efficiency level). ${ }^{14}$ All costs were reported in international dollars (\$Int) for the year 2005 to facilitate more meaningful comparisons across regions ( $\$$ Int1 buys the same quantity of healthcare resources in the sub-Saharan African and South East Asian regions as it does in the United States). For example, cost estimates in sub-Saharan Africa in \$Int should be divided by a factor 2.3 to obtain US \$ cost estimates for Kenya (in South East Asia cost estimates should be divided by a factor 3.1 to obtain US\$ cost estimates for India). ${ }^{15}$ All costs and effects are discounted at $3 \%$, following standardised WHO-CHOICE analysis. $^{14}$

\section{Estimating cost effectiveness}

We rank ordered interventions on the basis of their cost effectiveness in a number of standardised steps. ${ }^{14}$ Firstly, within each disease area, we calculated the average cost effectiveness ratios for every intervention by dividing its total number of DALYs averted by its total costs. Secondly, again within each disease area, we considered only those interventions that were both more effective and less costly than other interventions. We then calculated the incremental cost effectiveness ratio for those resulting interventions by dividing the incremental costs by the incremental health effects. The economic attractiveness of an intervention within its disease area is reflected by this incremental cost effectiveness ratio: the lower the incremental cost per DALY averted, the more economically attractive an intervention is. Thirdly, we compared resulting interventions across disease areas on the basis of their incremental cost effectiveness ratios and ranked them accordingly. The interventions with the lowest incremental cost effectiveness ratio are ranked highest and are economically most attractive.

WHO-CHOICE defines interventions that have an incremental cost effectiveness ratio of less than the gross domestic product (GDP) per capita as very cost effective, and those with a ratio less than three times the GDP per capita as cost effective. The regions studied here have a GDP of around $\$$ Int 2000 per capita, ${ }^{30}$ which means that interventions costing $<\$$ Int2000 per DALY averted can be considered very cost effective and those costing between \$Int2000 and \$Int6000 can be considered cost effective. Other interventions are considered not cost effective.

\section{Uncertainty analysis}

All interventions are imbued with a certain degree of uncertainty. To handle this aspect of reporting for such a wide range of interventions, we classified interventions according to their degree of cost effectiveness (not cost effective, cost effective, or very cost effective) in order to ascertain order of magnitude differences in cost effectiveness. In addition, we undertook a probabilistic uncertainty analysis using MCLeague software ${ }^{31}$ to assess the impact of alternative assumptions on costs and effects (which were each varied with plus and minus $25 \%$ of their baseline values) on the classification of interventions.

\section{Model adaptations}

A few modifications were made to previously published analyses. ${ }^{9-12}$ Firstly, interventions were considered during the 10 year period 2005to 2015 rather than the period 2000-10, and costs were reported at price levels for year 2005 instead of 2000 . Secondly, because of variations in the reporting of coverage levels in previous studies, interventions were evaluated at standardised geographic coverage levels of $50 \%, 80 \%$, and $95 \%$. Thirdly, assumptions on screening, patient, training, and intervention programme costs were revisited to make results consistent across the analysis. For example, recent price reductions of azithromycin after patent expiry were included in the analysis on trachoma control.

\section{Results}

Following the stepwise approach to the rank ordering of interventions on the basis of their cost effectiveness, we first report the average cost effectiveness ratios of all interventions within each disease area (appendix table B1 on bmj.com).

Second, we report the incremental cost effectiveness ratios for those interventions that both cost less and provide more health effects than other interventions, and these indicate the economic attractiveness of interventions within each disease area (same table).

In trachoma control, trichiasis surgery is the most cost effective intervention, followed by mass treatment with azithromycin in both regions. Both mass treatment with tetracycline ointment and targeted treatment with azithromycin are not cost effective. In cataract control, extracapsular cataract surgery dominates 
intracapsular surgery in both regions. In both regions, passive screening of children and adults for hearing disorders (in combination with provision of hearing aids) is most cost effective, followed by screening of adults every five years and annual screening of primary and secondary school children. Screening of adults every 10 years is not cost effective. For treatment of chronic otitis media, treatment with topical antibiotics is the most cost effective intervention in both regions. For screening for refractive error (including the provision of spectacles), screening of all primary and secondary school children is most cost effective in sub-Saharan Africa. In South East Asia, screening of secondary school children is most cost effective, followed by screening of both primary and secondary school children.

In a third step, we rank interventions according to their incremental cost effectiveness ratio across all disease areas (tables $4 \Downarrow$ and $5 \Downarrow$ for sub-Saharan Africa and South East Asia). This is illustrated in the figure $\Downarrow$ for sub-Saharan Africa. Implementation of all cost effective interventions would cost around \$Int19 per capita in sub-Saharan Africa.

In both regions treatment of chronic otitis media with topical antibiotics is the most cost effective intervention, with an average cost per DALY averted of $<\$$ Int63 at all levels. In sub-Saharan Africa the next most cost effective interventions are trichiasis surgery, extracapsular cataract surgery, annual screening of all primary and secondary school children for refractive error, and treatment for meningitis with ceftriaxione. In South East Asia the next most cost effective interventions are treatment of meningitis with ceftriaxione, extracapsular cataract surgery, screening of all primary and secondary school children for refractive error, and trichiasis surgery. In both regions these interventions all cost $<\$$ Int 285 per DALY averted (incremental cost effectiveness ratio, with the exact order of interventions dependent on coverage level). In both regions introducing screening for hearing impairment in combination with the delivery of hearing aids, at $80 \%$ coverage level costs around $\$$ Int 1000 per DALY averted. According to WHO-CHOICE benchmark on cost effectiveness, these interventions can all be considered very cost effective. Mass treatment with azithromycin is the least cost effective intervention in both regions but can, depending on the coverage level, still be considered cost effective in the sub-Saharan African region. In the absence of any budgetary constraint implementation of all interventions would lead to a total health gain of up to 32 million DALYs in sub-Saharan Africa and 84 million DALYs in South East Asia.

The probabilistic uncertainty analysis depicted in appendix C on bmj.com shows the impact of plausible variations in total costs and total effects and shows that the average cost effectiveness ratios of most interventions would retain their classification of highly cost effective or cost effective after taking into account such uncertainty. A similar logic would apply to the incremental cost effectiveness ratio.

\section{Discussion}

\section{Principal findings}

Treatment of chronic otitis media, extracapsular cataract surgery, trichiasis surgery, treatment for meningitis, and annual screening of school children for refractive error are among the most cost effective interventions available to control hearing and vision impairment, with the cost per DALY averted $<\$$ Int 285 in both regions. Screening of both schoolchildren (annually) and adults (every five years) for hearing loss costs around $\$$ Int 1000 per DALY averted. These interventions can be considered highly cost effective. Mass treatment with azithromycin to control trachoma can be considered cost effective in the sub-Saharan African but not the South East Asian region.

\section{Strengths and limitations}

The analysis has several limitations. Firstly, we performed our analysis at the regional level, but important differences in costs or effectiveness of interventions may exist between countries in the same region. Since decision making is made at the country (as opposed to regional) level, more refined estimates of costs, effects, and cost effectiveness should be made at the country level, based on country-specific data. A good example is the contextualisation of WHO-CHOICE regional results to the country level in Mexico, as reported in this series. ${ }^{32}$

Secondly, assumptions on intervention effectiveness are based on a variety of sources and may reflect contexts other than the regions analysed - the same level of effectiveness may not always be realised in reality, and results should be interpreted with caution. Yet, our probabilistic uncertainty analysis indicates that our study results are robust to alternative assumptions. These issues are discussed in detail in previously published papers. ${ }^{9-12}$

Thirdly, we did not evaluate all possible interventions that could reduce vision or hearing loss, and our choice of interventions is somewhat arbitrary. Policymakers should be aware of this, and should not limit their choice of interventions to those included in this analysis.

Fourthly, and more specifically, we evaluated screening for hearing disorders as carried out by trained primary health workers (incurring healthcare costs), and screening for refractive error as carried out by trained school teachers (who incur no healthcare costs). However, alternative assumptions have only limited impact on study results.

Fifthly, in the absence of reliable data, we did not include time costs of people seeking and undergoing care, nor did we include changes in productivity losses as a result of the interventions. The perspective of analysis is therefore not truly societal. Inclusion of productivity gains after reductions in vision and hearing loss would render the interventions more cost effective. Sixthly, we assumed that all interventions were implemented at a relatively high efficiency level—which allows an equal comparison between the cost effectiveness of interventions and avoids the complications from interventions that were not implemented well would be disadvantaged in comparison with those that were well implemented.

Lastly, the analysis evaluates interventions at 50\%, 80\%, and $95 \%$ geographic coverage levels, following standardised WHO-CHOICE methodology. The higher coverage levels may not always be achievable but are included to indicate the economies of scale that may take place when more people are reached with an intervention. ${ }^{23}$

The above limitations should be considered in the overall aim of WHO-CHOICE analysis to provide broad indications on the cost effectiveness of a range of interventions to inform general policy discussions, rather than to deliver precise estimates on a specific intervention. ${ }^{15}$

Study strengths include the use of disease models that have already been published and applied, consideration of combinations of interventions, use of a generic measure of effectiveness, and testing of important assumptions through sensitivity analyses. 


\section{Comparison with other studies}

This study includes a number of modifications in comparison to the previously published analysis. The higher 2005 price levels have generally resulted in higher cost effectiveness ratios, but these and other modifications have generally not changed study conclusions. The exception is mass or targeted treatment with azithromycin in trachoma control, where price reductions of azithromycin have offset general price increases in the period from 2000 to 2005 and have thus rendered the interventions more cost effective.

\section{Policy implications}

Our results have four major policy implications. Firstly, they reinforce the fact that cataract surgery and treatment of chronic otitis media are among the key interventions for combating vision and hearing impairment.

Secondly, they show that there is a strong economic case to consider screening for refractive error among schoolchildren. This supports current efforts within the VISION 2020 initiative to give greater prominence to screening programmes. Screening schoolchildren and adults for hearing disorders is somewhat less cost effective but is still economically attractive according to commonly used benchmarks.

Thirdly, inclusion of mass treatment with azithromycin in programmes to eliminate trachoma needs careful analysis: although the intervention was cost effective in sub-Saharan Africa according to commonly used benchmarks, it was not in South East Asia. However, many programmes around the world use donated azithromycin, which makes the intervention economically more attractive than we have reported here. In our analysis, trichiasis surgery is more cost effective and thus provides better value for money.

Fourth, our results show that substantial health gains can be achieved - up to 32 and 84 million DALYs averted in sub-Saharan Africa and South East Asia respectively, when available effective interventions are scaled up. This will require major resource mobilisation efforts at domestic and international level. Yet, whether such substantial investments are warranted can only be judged when the findings our present study-that vision and hearing impairment control interventions are generally cost effective-are considered in relation to the economic attractiveness of other, existing or new, interventions in health. For this broader analysis, we refer to Evans et $\mathrm{al}^{15}$ and Chisholm et al, ${ }^{33}$ who compare the economic attractiveness of a wide range of interventions to control, respectively, communicable and non-communicable diseases.

Contributors: Both authors contributed to the conception, design and interpretation of data, and drafting of the manuscript. RB performed the technical analysis. Both authors approved the submitted version of the manuscript. RB is the guarantor of the manuscript.

Competing interests: All authors have completed the Unified Competing Interest form at www.icmje.org/coi_disclosure.pdf (available on request from the corresponding author) and declare: no support from any organisation for the submitted work; no financial relationships with any organisations that might have an interest in the submitted work in the previous three years, no other relationships or activities that could appear to have influenced the submitted work.

Ethical approval: Ethical approval was not required for this study.

Data sharing: No additional data available
1 World Health Organization. Fact sheet-magnitude and causes of visual impairment . WHO, 2011. www.who.int/mediacentre/factsheets/ss282/en/.

2 Mathers C, Smith A, Concha M. Global burden of hearing loss in the year 2000. WHO, 2002. www.who.int/healthinfo/statistics/bod_hearingloss.pdf .

3 Mathers C, Smith A, Concha M. Global burden of adult-onset hearing loss in the year 2002. WHO, 2005

4 Smith A, Mathers C. Epidemiology of infection as a cause of hearing loss. In: Newton VE, Vallely PJ, eds. Infection and hearing impairment . John Wiley, 2006.

5 Mackenzie I, Smith A. Deafness-the neglected and hidden disability. Ann Trop Med Parasitol 2009;103:565-71

6 World Health Organization. Fact sheet—deafness and hearing impairment. WHO, 2011. www.who.int/mediacentre/factsheets/fs300/en/index.html.

7 Vision 2020. Global initiative for the elimination of avoidable blindness. 2011. www. vision2020.org.

8 World Health Organisation, World Wide Hearing 2009. Seventh workshop on provision of hearing aids and services for developing countries and WWHearing General Assembly. Report of workshop and general assembly. 12-13 November 2009. WHO, 2009.

9 Baltussen R, Sylla M, Mariotti SP. Cost-effectiveness analysis of cataract surgery: a global and regional analysis. Bull World Health Organ 2004;82:338-45.

10 Baltussen RM, Sylla M, Frick KD, Mariotti SP. Cost-effectiveness of trachoma control in seven world regions. Ophthalmic Epidemiol 2005;12:91-101.

11 Baltussen R, Naus J, Limburg H. Cost-effectiveness of screening and correcting refractive errors in school children in Africa, Asia, America and Europe. Health Policy 2009;89:201-15.

12 Baltussen R, Smith A. Cost-effectiveness of hearing impairment control in Africa and Asia: a mathematical modelling approach. Int $J$ Audiol 2009;48:144-58.

13 Hutubessy R, Chisholm D, Edejer TT. Generalized cost-effectiveness analysis for national-level priority-setting in the health sector. Cost Eff Resour Alloc 2003;1:8

14 Tan Torres, T, Baltussen RM, Adam T, Hutubessy RC, Acharya A, Evans DB. WHO guide to cost-effectiveness analysis. WHO, 2003

15 Evans DB, Lim SS, Adam T, Tan-Torres Edejer T, the WHO-CHOICE MDG Team. Achieving the Millennium Development Goals for health: a re-examination of intervention strategies. BMJ 2005;331:1457-61.

16 Resnikoff S, Pascolini D, Etya'ale D, Kocur I, Pararajasegaram R, Pokharel GP, et al. Global data on visual impairment in the year 2002. Bull World Health Organ 2004;82:844-51.

17 Resnikoff S, Pascolini D, Mariotti SP, Pokharel GP. Global magnitude of visual impairment caused by uncorrected refractive errors in 2004. Bull World Health Organ 2008;86:63-70.

18 World Health Organisation. The global burden of disease: 2004 update. Available at: www.who.int/healthinfo/global_burden_disease/2004_report_update/en/index.html.

19 Lauer JA, Murray CJL, Roehrich K, Wirth H. PopMod: a longitudinal four-state population model with two disease states and comorbidity. Cost Eff Resour Alloc 2003;1:6.

20 Murray CJL, Lopez A. Global burden of disease. World Bank, WHO, Harvard University, 1996.

21 International drug price indicator guide. Introduction. 2011. http://erc.msh.org/mainpage. $\mathrm{cfm}$ ?file $=1.0 . \mathrm{htm} \&$ module $=$ Dmp\&language $=$ English

22 Johns B, Baltussen R, Adam T, Hutubessy RCW. Programme costs in the economic evaluation of health interventions. Cost Eff Resour Alloc 2003;1:1.

23 Johns B, Baltussen R. Accounting for the costs of scaling up health interventions. Health Econ 2004;13:1117-24.

24 Adam T, Evans DB, Murray CJL. Econometric estimation of country-specific hospital costs. Cost Eff Resour Alloc 2003;1:3

25 Unicef. Database on school enrolment. 2008. www.unicef.org/infobycountry/india statistics.html.

26 Murray CJL, Lopez AD. The global burden of disease: a comprehensive assessment of mortality and disability from diseases, injuries, and risk factors in 1990 and projected to 2020. Harvard University Press, 1996.

27 Limburg H, Kansara HT, d'Souza S. Results of school eye screening of 5.4 million children in India - a five-year follow-up study. Acta Ophthalmol Scand 1999;77:310-4.

28 Hogeweg M, Sapkota YD, Foster A. Acceptability of aphakic correction. Results from Karnali eye camps in Nepal. Acta Ophthalmologica 1992;70:407-12.

29 Limburg H, Vaidyanathan K, Dalal HP. Cost-effective screening of schoolchildren for refractive errors. World Health Forum 1995;16:173-8.

30 Hutubessy RC, Baltussen RM, Evans DB, Barendregt JJ, Murray CJ. Stochastic league tables: communicating cost-effectiveness results to decision-makers. Health Econ 2001;10:473-7.

31 Salomon J, Carvalho N, Gutierrez-Delgado C, Casey A, Hogan DR, Lee D, et al. Intervention strategies to reduce burden of non-communicable diseases in Mexico: cost effectiveness analysis. BMJ 2012;344:e355.

32 Chisholm D, Baltussen, Evans DB, Ginsberg G, Lauer J, Lim S, et al. What are the priorities for prevention and control of non-communicable diseases and injuries in sub-Saharan Africa and South East Asia? BMJ 2012;344:e586.

33 Congdon N, Zheng M, Sharma A, Choi K, Song Y, Zhang M, et al. Prevalence and determinants of spectacle nonwear among rural Chinese secondary schoolchildren: the Xichang Pediatric Refractive Error Study Report 3. Arch Ophthalmol 2008;126:1717-23.

34 Vincent JE, Netek S, Parry A, Mladenovich D, Thein NN, Amendola PR. Reported wearing compliance of ready-made spectacles at 6 and 12 months. Optom Vis Sci 2010;87:958-65.

Accepted: 12 October 2011

\section{Cite this as: BMJ 2012;344:e615}

This is an open-access article distributed under the terms of the Creative Commons Attribution Non-commercial License, which permits use, distribution, and reproduction in any medium, provided the original work is properly cited, the use is non commercial and is otherwise in compliance with the license. See: http://creativecommons.org/licenses/by$\mathrm{nc} / 2.0 /$ and http://creativecommons.org/licenses/by-nc/2.0/legalcode. 


\section{What is already known on this topic}

Several studies have reported on the global and regional cost effectiveness of interventions targeting cataract, trachoma, refractive error and different causes of hearing impairment.

However, studies have been carried out in isolation, which prevents the cost effectiveness of the different interventions in visual and hearing impairment control being directly compared.

In addition, these studies have been analysed using year 2000 demographics and price levels

\section{What this study adds}

This study directly compares cost and effects of interventions targeting cataract, trachoma, refractive error and different causes of hearing impairment, using more recent price levels in Sub-Saharan Africa and South East Asia

This allows the identification of most efficient strategies to reduce vision and hearing loss

\section{Tables}

\begin{tabular}{|c|c|c|c|}
\hline & AfrE & SearD & World \\
\hline Total population* & 402 & 1388 & 6502 \\
\hline \multicolumn{4}{|l|}{ Visual impairment $\dagger$} \\
\hline \multicolumn{4}{|l|}{ Blindness: } \\
\hline Cataract & $2.00(0.50)$ & $4.25(0.31)$ & $17.62(0.27)$ \\
\hline Glaucoma & $0.55(0.14)$ & $0.75(0.05)$ & $4.53(0.07)$ \\
\hline Age related macular degeneration & 0 & $0.42(0.03)$ & $3.21(0.05)$ \\
\hline Corneal opacities & $0.44(0.11)$ & $0.25(0.02)$ & $1.88(0.03)$ \\
\hline Diabetic retinopathy & 0 & $0.25(0.02)$ & $1.77(0.03)$ \\
\hline Childhood blindness & $0.20(0.05)$ & $0.40(0.03)$ & $1.44(0.02)$ \\
\hline Trachoma & $0.27(0.07)$ & $0.14(0.01)$ & $1.33(0.02)$ \\
\hline Onchocerciasis & $0.07(0.02)$ & 0 & $0.29(0.00)$ \\
\hline Uncorrected refractive errorł & $0.62(0.15)$ & $3.98(0.29)$ & $6.84(0.11)$ \\
\hline Others & $0.12(0.03)$ & $1.88(0.14)$ & $4.79(0.07)$ \\
\hline Total & $4.26(1.06)$ & $12.32(0.89)$ & $43.74(0.67)$ \\
\hline \multicolumn{4}{|l|}{ Low vision: } \\
\hline Unspecified & $10.57(2.63)$ & $28.44(2.05)$ & $124.26(1.91)$ \\
\hline Uncorrected refractive error & $1.64(0.41)$ & $36.28(2.61)$ & $87.94(1.35)$ \\
\hline Total & $12.21(3.04)$ & $64.72(4.66)$ & $212.20(3.26)$ \\
\hline \multicolumn{4}{|c|}{ Moderate or greater hearing impairment ${ }^{\star}$} \\
\hline Adult onset & $5.91(1.47)$ & $51.80(3.73)$ & $207.28(3.19)$ \\
\hline Child onset & $8.63(2.15)$ & $14.38(1.04)$ & $46.15(0.71)$ \\
\hline Total & $14.54(3.62)$ & $66.18(4.77)$ & $253.42(3.90)$ \\
\hline
\end{tabular}

${ }^{*}$ Based on 2004 burden of disease estimates. ${ }^{18}$

†Based on Resnikoff et al. ${ }^{1617}$ Figures relate to year 2004 and do not match with figures on year 2010 as provided in main text (the latter figures are not yet available by cause).

fEstimates in absolute numbers are for ages $\geq 50$ years. Percentages are compared with total population of all ages. 


\begin{tabular}{|c|c|}
\hline Intervention code & Intervention description \\
\hline \multicolumn{2}{|l|}{ Trachoma control } \\
\hline TRA-1 & Mass treatment tetracycline ointment ( $50 \%$ coverage) \\
\hline TRA-2 & Mass treatment azithromycin ( $50 \%$ coverage) \\
\hline TRA-3 & Targeted treatment azithromycin ( $50 \%$ coverage) \\
\hline TRA-4 & Trichiasis surgery $(50 \%$ coverage) \\
\hline TRA-5 & Mass treatment tetracycline ointment + trichiasis surgery ( $50 \%$ coverage) \\
\hline TRA-6 & Mass treatment azithromycin + trichiasis surgery $(50 \%$ coverage $)$ \\
\hline TRA-7 & Targeted treatment azithromycin + trichiasis surgery ( $50 \%$ coverage) \\
\hline TRA-8 & Mass treatment tetracycline ointment ( $80 \%$ coverage) \\
\hline TRA-9 & Mass treatment azithromycin ( $80 \%$ coverage) \\
\hline TRA-10 & Targeted treatment azithromycin ( $80 \%$ coverage) \\
\hline TRA-11 & Trichiasis surgery $(80 \%$ coverage) \\
\hline TRA-12 & Mass treatment tetracycline ointment + trichiasis surgery ( $80 \%$ coverage) \\
\hline TRA-13 & Mass treatment azithromycin + trichiasis surgery $(80 \%$ coverage) \\
\hline TRA-14 & Targeted treatment azithromycin + trichiasis surgery ( $80 \%$ coverage) \\
\hline TRA-15 & Mass treatment tetracycline ointment (95\% coverage) \\
\hline TRA-16 & Mass treatment azithromycin (95\% coverage) \\
\hline TRA-17 & Targeted treatment azithromycin (95\% coverage) \\
\hline TRA-18 & Trichiasis surgery (95\% coverage) \\
\hline TRA-19 & Mass treatment tetracycline ointment + trichiasis surgery ( $95 \%$ coverage) \\
\hline TRA-20 & Mass treatment azithromycin + trichiasis surgery (95\% coverage) \\
\hline TRA-21 & Targeted treatment azithromycin + trichiasis surgery (95\% coverage) \\
\hline \multicolumn{2}{|l|}{ Cataract control } \\
\hline СAT-4 & Extracapsular cataract extraction with posterior chamber lens implant ( $50 \%$ coverage) \\
\hline CAT-5 & Extracapsular cataract extraction with posterior chamber lens implant ( $80 \%$ coverage) \\
\hline СAT-6 & Extracapsular cataract extraction with posterior chamber lens implant (95\% coverage) \\
\hline \multicolumn{2}{|c|}{ Screening for hearing loss $t$} \\
\hline HEA-1 & Annual screening primary school children ( $50 \%$ coverage) \\
\hline HEA-2 & Annual screening secondary school children ( $50 \%$ coverage) \\
\hline HEA-3 & Annual screening primary and secondary school children ( $50 \%$ coverage) \\
\hline HEA-4 & Screening adults every 5 years ( $50 \%$ coverage) \\
\hline HEA-5 & Screening adults every 10 years ( $50 \%$ coverage) \\
\hline HEA-6 & Passive screening all children and adults ( $50 \%$ coverage) \\
\hline HEA-7 & Annual screening primary school children + screening adults every 5 years ( $50 \%$ coverage) \\
\hline HEA-8 & Annual screening primary school children + screening adults every 10 years ( $50 \%$ coverage) \\
\hline HEA-9 & Annual screening secondary school children + screening adults every 5 years ( $50 \%$ coverage) \\
\hline HEA-10 & Annual screening secondary school children + screening adults every 10 years ( $50 \%$ coverage) \\
\hline HEA-11 & Annual screening primary and secondary school children + screening adults every 5 years ( $50 \%$ coverage) \\
\hline HEA-12 & Annual screening primary and secondary school children + screening adults every 10 years ( $50 \%$ coverage) \\
\hline HEA-13 & Annual screening primary school children ( $80 \%$ coverage) \\
\hline HEA-14 & Annual screening secondary school children $(80 \%$ coverage $)$ \\
\hline HEA-15 & Annual screening primary and secondary school children ( $80 \%$ coverage) \\
\hline HEA-16 & Screening adults every 5 years ( $80 \%$ coverage) \\
\hline HEA-17 & Screening adults every 10 years ( $80 \%$ coverage) \\
\hline HEA-18 & Passive screening all children and adults ( $80 \%$ coverage) \\
\hline HEA-19 & Annual screening primary school children + screening adults every 5 years ( $80 \%$ coverage) \\
\hline HEA-20 & Annual screening primary school children + screening adults every 10 years ( $80 \%$ coverage) \\
\hline HEA-21 & Annual screening secondary school children + screening adults every 5 years ( $80 \%$ coverage) \\
\hline
\end{tabular}




\section{Table 2 (continued)}

\begin{tabular}{|c|c|}
\hline Intervention code & Intervention description \\
\hline HEA-22 & Annual screening secondary school children + screening adults every 10 years ( $80 \%$ coverage) \\
\hline HEA-23 & Annual screening primary and secondary school children + screening adults every 5 years ( $80 \%$ coverage) \\
\hline HEA-24 & Annual screening primary and secondary school children + screening adults every 10 years ( $80 \%$ coverage) \\
\hline HEA-25 & Annual screening primary school children ( $95 \%$ coverage) \\
\hline HEA-26 & Annual screening secondary school children (95\% coverage) \\
\hline HEA-27 & Annual screening primary and secondary school children ( $95 \%$ coverage) \\
\hline HEA-28 & Screening adults every 5 years (95\% coverage) \\
\hline HEA-29 & Screening adults every 10 years ( $95 \%$ coverage) \\
\hline HEA-30 & Passive screening all children and adults ( $95 \%$ coverage) \\
\hline HEA-31 & Annual screening primary school children + screening adults every 5 years ( $95 \%$ coverage) \\
\hline HEA-32 & Annual screening primary school children + screening adults every 10 years ( $95 \%$ coverage) \\
\hline HEA-33 & Annual screening secondary school children + screening adults every 5 years (95\% coverage) \\
\hline HEA-34 & Annual screening secondary school children + screening adults every 10 years (95\% coverage) \\
\hline HEA-35 & Annual screening primary and secondary school children + screening adults every 5 years ( $95 \%$ coverage) \\
\hline HEA-36 & Annual screening primary and secondary school children + screening adults every 10 years ( $95 \%$ coverage) \\
\hline \multicolumn{2}{|l|}{ Meningitis } \\
\hline MEN-1 & Ceftriaxione $(50 \%$ coverage $)$ \\
\hline MEN-2 & Ceftriaxione $(80 \%$ coverage $)$ \\
\hline MEN-3 & Ceftriaxione $(95 \%$ coverage $)$ \\
\hline \multicolumn{2}{|c|}{ Chronic otitis media control } \\
\hline COM-1 & Aural toilet ( $50 \%$ coverage) \\
\hline COM-2 & Topical antibiotics ( $50 \%$ coverage) \\
\hline COM-3 & Aural toilet ( $80 \%$ coverage) \\
\hline COM-4 & Topical antibiotics ( $80 \%$ coverage) \\
\hline COM-5 & Aural toilet ( $95 \%$ coverage) \\
\hline COM-6 & Topical antibiotics (95\% coverage) \\
\hline \multicolumn{2}{|c|}{ Uncorrected refractive errorł } \\
\hline $\mathrm{RE}-1$ & Annual screening all primary school children ( $50 \%$ coverage) \\
\hline $\mathrm{RE}-2$ & Annual screening all secondary school children ( $50 \%$ coverage) \\
\hline RE-3 & Annual screening all primary and secondary school children ( $50 \%$ coverage) \\
\hline $\mathrm{RE}-4$ & Annual screening children 8 years old ( $50 \%$ coverage) \\
\hline $\mathrm{RE}-5$ & Annual screening children 13 years old ( $50 \%$ coverage) \\
\hline $\mathrm{RE}-6$ & Annual screening children 8 and 13 years old ( $50 \%$ coverage) \\
\hline RE-7 & Annual screening all primary school children ( $80 \%$ coverage) \\
\hline $\mathrm{RE}-8$ & Annual screening all secondary school children ( $80 \%$ coverage) \\
\hline RE-9 & Annual screening all primary and secondary school children ( $80 \%$ coverage) \\
\hline $\mathrm{RE}-10$ & Annual screening children 8 years old ( $80 \%$ coverage) \\
\hline RE-11 & Annual screening children 13 years old ( $80 \%$ coverage) \\
\hline RE-12 & Annual screening children 8 and 13 years old ( $80 \%$ coverage) \\
\hline $\mathrm{RE}-13$ & Annual screening all primary school children (95\% coverage) \\
\hline $\mathrm{RE}-14$ & Annual screening all secondary school children ( $95 \%$ coverage) \\
\hline RE-15 & Annual screening all primary and secondary school children ( $95 \%$ coverage) \\
\hline RE-16 & Annual screening children 8 years old ( $95 \%$ coverage) \\
\hline RE-17 & Annual screening children 13 years old ( $95 \%$ coverage) \\
\hline $\mathrm{RE}-18$ & Annual screening children 8 and 13 years old (95\% coverage) \\
\hline
\end{tabular}

*Coverage level relates to the geographic coverage of these eligible for intervention.

†Screening for hearing loss is in combination with the provision of hearing aids to those who need it.

$\ddagger$ Screening for uncorrected refractive error is in combination with the provision of spectacles to those who need it. 
Table 3| Model inputs for cost effectiveness analysis of screening strategies for uncorrected refractive error in schoolchildren in WHO sub-Saharan African sub-region AfrE

\begin{tabular}{|c|c|c|}
\hline Variable & Assumption & Data source \\
\hline \multicolumn{3}{|l|}{ Target population } \\
\hline Primary school enrolment rate & $63 \%$ & Unicef $^{25}$ \\
\hline Secondary school enrolment rate & $27 \%$ & Unice $^{25}$ \\
\hline \multicolumn{3}{|l|}{ Health effects } \\
\hline Health state valuation of visual impairment & 0.755 & Burden of disease study ${ }^{26}$ \\
\hline $\begin{array}{l}\text { Remission rate of uncorrected refractive error (without screening or } \\
\text { treatment) }\end{array}$ & 0 & Assumption $^{*}$ \\
\hline Remission rate of uncorrected refractive error (intervention scenarios) & 1.09 & Calculationt \\
\hline Compliance with wearing provided glassess & $70 \%$ & $\begin{array}{l}\text { Assumption based on Limburg et } \mathrm{al}^{27} \text { in India; } \\
\text { Hogeweg et } \mathrm{al}^{28} \text { in Nepalł }\end{array}$ \\
\hline \multicolumn{3}{|l|}{ Costs (\$Int) } \\
\hline \multicolumn{3}{|l|}{ Training§: } \\
\hline No of children to screen per teacher (5-10 years old) & 165 & \multirow[t]{4}{*}{ Limburg et $\mathrm{al}^{29}$ in Indiađ } \\
\hline No of children to screen per teacher ( 8 years old) & 50 & \\
\hline No of children to screen per teacher (11-15 years old) & 165 & \\
\hline No of children to screen per teacher ( 13 years old) & 100 & \\
\hline Duration of training (days) & 1 & Assumption $^{*}$ \\
\hline Repetition of training (every number of years) & 5 & Assumption* $^{*}$ \\
\hline Cost per teacher to train (cost per day) & 45 & WHO-CHOICE \\
\hline \multicolumn{3}{|l|}{ Screening costs: } \\
\hline Ratio of true positive:false positive cases & $1: 3.6$ & Limburg et a $\left.\right|^{29}$ in Indiađ \\
\hline Useful life of glasses (years) & 4 & Assumption $^{*}$ \\
\hline Screening material costs (tape, card etc) & 10 & Assumption* $^{*}$ \\
\hline \multicolumn{3}{|l|}{ Treatment at health clinic: } \\
\hline \multicolumn{3}{|l|}{ Cost of ophthalmic assistant: } \\
\hline Time spent per patient (minutes) & 15 & Assumption $^{*}$ \\
\hline Annual salary & 7968 & WHO-CHOICE \\
\hline \multicolumn{3}{|l|}{ Costs of ophthalmic equipment: } \\
\hline Costs of set & 4 & WHO-CHOICE \\
\hline Useful life (years) & 10 & Assumption* $^{*}$ \\
\hline Average annual patient load & 6400 & Assumption $^{*}$ \\
\hline \multicolumn{3}{|l|}{ Costs of spectacles: } \\
\hline Purchase price & 5 & Assumption* \\
\hline Useful life (years) & 4 & Assumption $^{*}$ \\
\hline \multicolumn{3}{|l|}{ Costs of outpatient visits: } \\
\hline No of visits & 4.6 & Limburg et a $\left.\right|^{29}$ in India \\
\hline Costs of visits at secondary hospital level & 500 & WHO-CHOICE \\
\hline Discount rate & $3 \%$ & WHO-CHOICE \\
\hline
\end{tabular}

*Based on personal communication with Dr Mariotti (WHO) and Dr Limburg (independent consultant), both specialists in ophthalmology in low and middle income settings.

†Formula is - $\mathrm{LN}(1-($ effectiveness $\times$ coverage)), with effectiveness equal to compliance and coverage as defined in intervention. The table lists the remission rate for a coverage of $95 \%$.

‡Estimates based on two studies in the respective regions, and are in line with findings from other studies in China ${ }^{34}$ and Thailand. ${ }^{35}$

$\S$ The number of teachers to train depends on the number of schoolchildren that one teacher can screen and, ultimately, on school size. In screening of children aged 5-10 years, a trained teacher can serve all classes in the school, on average 165 children. In case only children of aged 8 years are screened, the teacher can screen only that class, on average 50 children. The same logic applies to screening at secondary school.

ITo our knowledge, this is the only study that provides the required details on costs of screening for refractive error in a low income setting and has therefore been used as the basis for our estimates. 


\begin{tabular}{|c|c|c|c|c|c|}
\hline \multirow[b]{2}{*}{ Disease area and intervention } & \multirow[b]{2}{*}{ Coverage (\%) } & \multirow{2}{*}{$\begin{array}{l}\text { Annual cost per } \\
\text { capita (\$Int) }\end{array}$} & \multirow{2}{*}{$\begin{array}{l}\text { Annual DALYs } \\
\text { saved per million } \\
\text { population }\end{array}$} & \multicolumn{2}{|c|}{ Cost effectiveness ratio } \\
\hline & & & & Average* $^{*}$ & Incremental† \\
\hline COM-2: Chronic otitis media, topical antibiotics & 50 & 0.01 & 535 & 16 & 16 \\
\hline COM-4: Chronic otitis media, topical antibiotics & 80 & 0.01 & 638 & 17 & 24 \\
\hline COM-6: Chronic otitis media, topical antibiotics & 95 & 0.01 & 670 & 20 & 63 \\
\hline TRA-11: Trachoma, trichiasis surgery & 80 & 0.42 & 5843 & 71 & 71 \\
\hline $\begin{array}{l}\text { CAT-4: Cataract, extracapsular cataract extraction } \\
\text { with posterior chamber lens implant }\end{array}$ & 80 & 0.64 & 5486 & 116 & 116 \\
\hline $\begin{array}{l}\text { CAT-6: Cataract, extracapsular cataract extraction } \\
\text { with posterior chamber lens implant }\end{array}$ & 95 & 0.73 & 6281 & 116 & 117 \\
\hline TRA-18: Trachoma, trichiasis surgery & 95 & 0.62 & 6939 & 90 & 189 \\
\hline $\begin{array}{l}\text { RE-9: Uncorrected refraction error, annual } \\
\text { screening of all schoolchildren } \neq\end{array}$ & 80 & 0.25 & 1306 & 190 & 190 \\
\hline MEN-1: Meningitis, ceftriaxione & 50 & 0.55 & 2534 & 217 & 217 \\
\hline $\begin{array}{l}\text { RE-15: Uncorrected refraction error, annual } \\
\text { screening of all schoolchildren } \neq\end{array}$ & 95 & 0.38 & 1551 & 242 & 521 \\
\hline $\begin{array}{l}\text { HEA-6: Hearing loss, passive screening of all } \\
\text { children and adults§ }\end{array}$ & 50 & 0.79 & 1075 & 735 & 735 \\
\hline $\begin{array}{l}\text { HEA-18: Hearing loss, passive screening of all } \\
\text { children and adults§ }\end{array}$ & 80 & 1.28 & 1719 & 747 & 766 \\
\hline $\begin{array}{l}\text { HEA-4: Hearing loss, screening of adults every } 5 \\
\text { years§ }\end{array}$ & 50 & 3.67 & 4686 & 784 & 806 \\
\hline $\begin{array}{l}\text { HEA-16: Hearing loss, screening of adults every } \\
5 \text { years§ }\end{array}$ & 80 & 6.04 & 7497 & 806 & 843 \\
\hline MEN-2: Meningitis, ceftriaxione & 80 & 0.71 & 2702 & 263 & 959 \\
\hline $\begin{array}{l}\text { HEA-23: Hearing loss, annual screening of } \\
\text { schoolchildren + screening of adults every } 5 \\
\text { years§ }\end{array}$ & 80 & 8.32 & 9588 & 868 & 1089 \\
\hline $\begin{array}{l}\text { TRA-20: Trachoma, mass treatment with } \\
\text { azithromycin + trichiasis surgery }\end{array}$ & 95 & 1.29 & 7191 & 180 & 2654 \\
\hline MEN-3: Meningitis, ceftriaxione & 95 & 0.89 & 2760 & 322 & 3066 \\
\hline $\begin{array}{l}\text { HEA-35: Hearing loss, annual screening of school } \\
\text { children + screening of adults every } 5 \text { years } \S\end{array}$ & 95 & 14.86 & 11386 & 1305 & 3639 \\
\hline
\end{tabular}

DALYs=disability adjusted life years. \$Int=international dollars.

* $\$$ Int per DALY averted relative to no intervention.

†\$nt per DALY averted, within intervention cluster. This measures the increase in cost divided by the increase in effects when a new intervention is added to an existing intervention. For example, the incremental cost per DALY averted for screening primary and secondary school children for refractive error is the total increase in cost divided by the total increase in DALYs averted when screening of primary school children is added to the existing screening of secondary school children. Incremental ratios are only shown for interventions that are both more effective and less costly than other interventions.

$\ddagger$ Screening for uncorrected refractive error is in combination with the provision of spectacles to those who need it.

$\S$ Screening for hearing loss is in combination with the provision of hearing aids to those who need it. 


\begin{tabular}{|c|c|c|c|c|c|}
\hline \multirow[b]{2}{*}{ Disease area and intervention } & \multirow[b]{2}{*}{ Coverage (\%) } & \multirow{2}{*}{$\begin{array}{l}\text { Annual cost per } \\
\text { capita (\$Int) }\end{array}$} & \multirow{2}{*}{$\begin{array}{l}\text { Annual DALYs } \\
\text { saved per million } \\
\text { population }\end{array}$} & \multicolumn{2}{|c|}{ Cost effectiveness ratio } \\
\hline & & & & Average* $^{*}$ & Incremental† \\
\hline COM-2: Chronic otitis media, topical antibiotics & 50 & 0.01 & 507 & 14 & 14 \\
\hline COM-4: Chronic otitis media, topical antibiotics & 80 & 0.01 & 604 & 14 & 17 \\
\hline COM-6: Chronic otitis media, topical antibiotics & 95 & 0.01 & 634 & 15 & 24 \\
\hline MEN-1: Meningitis, ceftriaxione & 50 & 0.23 & 4030 & 56 & 56 \\
\hline $\begin{array}{l}\text { CAT-6: Cataract, extracapsular cataract extraction } \\
\text { with posterior chamber lens implant }\end{array}$ & 95 & 0.63 & 6447 & 97 & 97 \\
\hline MEN-2: Meningitis, ceftriaxione & 80 & 0.25 & 4269 & 58 & 100 \\
\hline $\begin{array}{l}\text { RE-2: Uncorrected refraction error, annual } \\
\text { screening of all secondary school children } \ddagger\end{array}$ & 50 & 0.18 & 1576 & 112 & 112 \\
\hline $\begin{array}{l}\text { RE-8: Uncorrected refraction error, annual } \\
\text { screening of all secondary school children } \ddagger\end{array}$ & 80 & 0.29 & 2522 & 114 & 116 \\
\hline $\begin{array}{l}\text { RE-9: Uncorrected refraction error, annual } \\
\text { screening of all schoolchildren } \neq\end{array}$ & 80 & 0.42 & 3405 & 122 & 147 \\
\hline MEN-3: Meningitis, ceftriaxione & 95 & 0.27 & 4352 & 62 & 244 \\
\hline TRA-11: Trachoma, trichiasis surgery & 80 & 0.27 & 943 & 285 & 285 \\
\hline $\begin{array}{l}\text { RE-15: Uncorrected refraction error, annual } \\
\text { screening of all schoolchildren } \neq\end{array}$ & 95 & 0.70 & 4044 & 173 & 444 \\
\hline $\begin{array}{l}\text { HEA-6: Hearing loss, passive screening of all } \\
\text { children and adults§ }\end{array}$ & 50 & 0.64 & 754 & 844 & 844 \\
\hline TRA-18: Trachoma, trichiasis surgery & 95 & 0.42 & 1120 & 374 & 849 \\
\hline $\begin{array}{l}\text { HEA-18: Hearing loss, passive screening of all } \\
\text { children and adults }\end{array}$ & 80 & 1.04 & 1207 & 862 & 892 \\
\hline $\begin{array}{l}\text { HEA-11: Hearing loss, annual screening of } \\
\text { schoolchildren }+ \text { screening of adults every } 5 \text { years } \S\end{array}$ & 50 & 4.99 & 5055 & 987 & 1027 \\
\hline $\begin{array}{l}\text { HEA-23: Hearing loss, annual screening of } \\
\text { schoolchildren + screening of adults every } 5 \text { years§ }\end{array}$ & 80 & 8.22 & 8088 & 1016 & 1063 \\
\hline $\begin{array}{l}\text { HEA-35: Hearing loss, annual screening of school } \\
\text { children + screening of adults every } 5 \text { years } \S\end{array}$ & 95 & 14.80 & 9605 & 1541 & 4340 \\
\hline $\begin{array}{l}\text { TRA-20: Trachoma, mass treatment with } \\
\text { azithromycin + trichiasis surgery }\end{array}$ & 95 & 0.93 & 1167 & 800 & 10860 \\
\hline
\end{tabular}

DALYs=disability adjusted life years. \$Int=international dollars.

*\$Int per DALY averted relative to no intervention.

† \$Int per DALY averted, within intervention cluster. This measures the increase in cost divided by the increase in effects when a new intervention is added to an existing intervention. For example, the incremental cost per DALY averted for screening primary and secondary school children for refractive error is the total increase in cost divided by the total increase in DALYs averted when screening of primary school children is added to the existing screening of secondary school children. Incremental ratios are only shown for interventions that are both more effective and less costly than other interventions.

¥Screening for hearing loss is in combination with the provision of spectacles to those who need it.

$\S$ Screening for uncorrected refractive error is in combination with the provision of hearing aids to those who need it. 


\section{Figure}

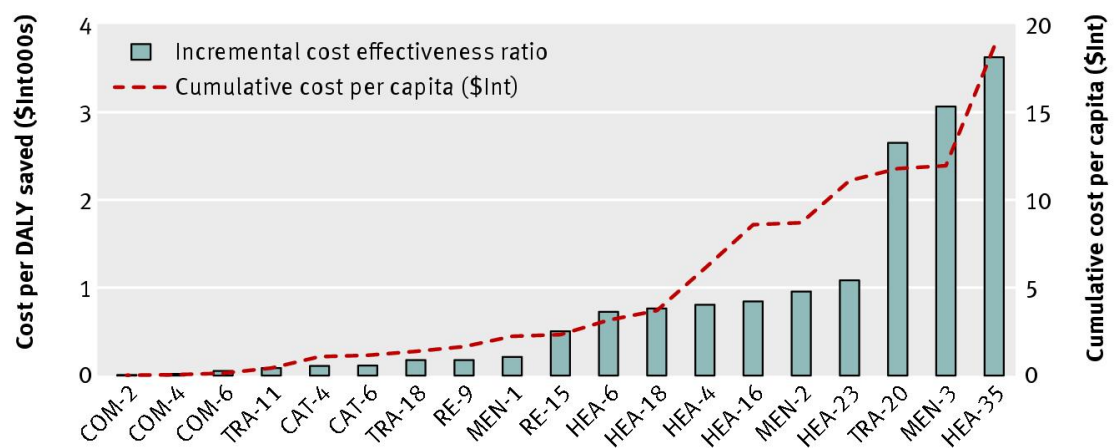

Incremental cost effectiveness ratios and cumulative cost per capita (\$Int) of interventions to combat vision and hearing loss in WHO sub-Saharan African sub-region AfrE. Cost per DALY averted (bars) ranges from very cost effective (such as treatment of chronic otitis media with topical antibiotics at 50\% coverage (COM-2) costing \$Int16 per DALY averted) to least cost effective (annual screening of schoolchildren and screening of adults every five years for hearing loss (HEA-35) costing \$Int3639 per DALY averted). Cumulative cost per capita (dashed line) shows cost if interventions are implemented in order of decreasing economic attractiveness. In case only COM-2 is implemented, cost per capita is $\$$ Int0.01. If all shown interventions are implemented, costs per capita increase to $\$$ Int14.86. See table $4 \Downarrow$ for descriptions of the intervention codes 